\title{
Social Capital or Social Debt in Healthcare?
}

\section{Receive social support for Indonesia' poor families when hospitalized}

\author{
$1^{\text {st }}$ FX Sri Sadewo \\ Sociology Department \\ Universitas Negeri Surabaya \\ Surabaya, Indonesia \\ fsadewo@unesa.ac.id
}

\author{
$2^{\text {nd }} M$. Setyo Pramono \\ Centre of Humaniora and Health Management \\ National Institute of Health Research and \\ Development (NIHRD) \\ Ministry of Health of the Republic ofIndonesia \\ Surabaya, Indonesia
}

\author{
$3^{\text {rd }}$ Refti Handini Listyani \\ Sociology Department \\ Universitas Negeri Surabaya \\ Surabaya, Indonesia \\ reftilistyani@unesa.ac.id
}

\begin{abstract}
For the poor, subsidized health insurance does not fully meet the needs at the time of illness. In a sick condition, let alone be hospitalized, help from the environment around the family becomes important. They struggle to free themselves from illness, so as not to worsen poverty. Through ethnographic research using illness narrative, the results show that the aid proved to be a burden for the community. The aid which is social capital becomes social debt for poor families. This conclusion resulted from the findings of poor families treated in the Sampang and Bantul' public hospitals. Although different ethnic backgrounds differ (Java and Madura), the poor continue to take this into account as social debt.
\end{abstract}

Keywords—social capital, social debt, hospitalized, poor.

\section{INTRODUCTION}

Sickness is one of Chambers' circles of poverty. In a state of illness, a person can not meet his basic needs. As a result, its economic structure collapsed.[1] Therefore, in various poverty eradication strategies, governments provide health access to the poor. The easiest way is to provide health insurance. The premium payments are subsidized by the government. This is a social guarantee advocated by the World Bank when the country faces a monetary crisis.[2]

Such a strategy is very effective in improving the health status of poor families. Poor families are more likely to use basic health insurance. This basic health insurance can effectively be subsidized by the government.[3] However, in certain diseases, basic health insurance is not profitable. People will be able to use full insurance, while the poor will experience physical vulnerability when suffering from chronic diseases, such as cancer.[4] This health insurance does affect the expenditure of the family. Being aware of this, the family is able to budget specifically health insurance. Meanwhile, poor families are more dependent on government subsidies in health insurance financing.[5] Health insurance is very useful again should be hospitalized. Falling ill and having hospitalization can result in more severe impoverishment. First, impoverishment occurs due to loss of income due to ill patients. The work of the patient and other family members is disrupted. Secondly, the patient's family must incur costs beyond the insurance claim, such as: transport and accommodation while waiting for the patient to be hospitalized (out of pocket).[2] This overall cost is known as the financial cost of illness. [6]

Meanwhile, a number of researchers have observed that every society develops and uses its social capital to address the problems it encounters, including physical vulnerability. It is also done to the poor.[2] In health problems, social capital proves to be beneficial. [7] Proximity to relatives and community support improves the quality of health, whether physical or mental. [8] Among the elderly (elderly) human groups, for example, improved quality of life occurs because of social capital, namely: family support, encourage to visit the hospital.[9], [10] Meanwhile, other research indicates that social capital can also be used for health intervention. Social capital plays a role in health promotion to vulnerable and / or poor community groups.[11], [12]

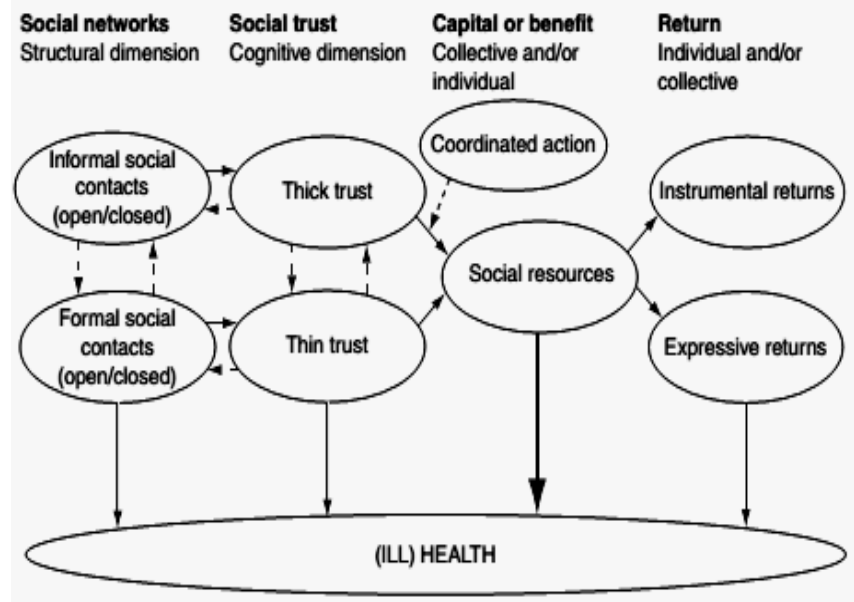

Fig. 1. Conceptual Framing of Social Capital roles for Health. By Mikael Rostila[13, p. 29] 
However, there are others who call the opposite. Social capital can also hamper. What is written by Alenjandro Portes that high social capital too demands individuals to support the others. High social capital also limits individual freedom with strong informal oversight.[14] This can be said to be beneficial, but also otherwise detrimental if the public health culture is not good. On the other hand, strong social capital provides an opportunity for the formation of dominant groups. This dominant group limits community members to access alternative health information and access. [15]

\section{RESEARCH METHOD}

Through an ethnographic approach, [16] in particular the phenomenological perspective (llness narrative) [17]-[19], this study reveals how construction of illness in poor families, especially when family members must be hospitalized. With in-depth interview techniques on patients and families of patients about when the doctor first decided to be hospitalized, the study described how social support, from relatives, neighbors and friends from the work environment, runs in helping patients and their families during hospitalization. Moreover, the research also explores how patients and their families respond to social assistance.

To obtain such exposure, this research takes place in Bantul Public Hospital (RSUD Panembahan Senapati) and Sampang Public Hospital (RSUD dr. Muhammad Zyn). There are several reasons for choosing both districts. First, from basic health research 2010 and 2013, the health status of the community is different. Sampang society is considered a moderate public health status, otherwise Bantul society are high. Second, although different ethnics (Java and Madura), there is a similar culture associated with social capital, namely mutual cooperation (gotong royong), like as nyapot in Maduranese [20] and sambatan in Javanese. [21]. Two things actually have the same meaning, namely social assistance at the time people experience disaster.

Informants were selected and taken as many as 10 people from 60 patients each hospital who became respondents. Sixty of these respondents were taken by availability. They are their patients and their families who are hospitalized for about a week at the hospital. They were asked to be interviewed first. Ten patients and informant families represent typical characteristics of the population, from sex, residential location (urban, suburban and rural), to illness (mild, chronic or childbearing). After the interview, the next stage is home visits to see the socio-economic and cultural conditions of the family and the surrounding environment. In addition to observation, the interview continues on family members.

\section{RESULT AND DISCUSSION}

\section{A. Illness as a Disaster}

"The poor should not get sick" This is the jargon that always appears in various internet media about health access for poor families. Honestly, the people of any economy do not want to deal with hospitals, especially for poor families. Hospitals, not healthy homes, are interpreted not necessarily meant to be a place to heal, but also to mean sick people. Meanwhile, sickness is judged differently for everyone. For the poor, sickness is a disaster. When experiencing physical weakness and staying in the hospital, the person becomes socially and economically inoperable for his family. If it happens to the person who is the main breadwinner, then immediately the family suffered economic collapse, slumped to the lowest point. Nevertheless, the family quickly tried to recover the economic conditions. Widianto case from Bantul for example, his activity soon replaced by his son. According to Anto's confession, he is lucky because his father always involves in the venture. It is not unintentional, the involvement of family members in the business is a way to minimize production costs. Family members do not need to be paid the same as others.

Although considered a disaster, sick was distinguished by the community, including poor families. Pain is put into the concept of space and time, both by the people of Javanese and Madurenese. With the concept of space and time, sick is rated as "disaster" and "necessity." For them, it is said to be a disaster in the event of a disease or whatever the cause is unplanned, ignorant, or unthinkable. When not planned and so on it is nothing else related to time. The incident happened suddenly like the accident experienced by Mr. Daryono (66 years). He suffered cracked bones on his feet from an accident.

TABle I. Social Construction of Patient And Their Family ABOUT "SICK/PAIN"

\begin{tabular}{|l|l|l|l|}
\hline No. & Characteristic & "Sick" as Disaster & "Sick" as Necessity \\
\hline \multirow{2}{*}{1.} & Cause & $\begin{array}{l}\text { Accident } \\
\text { Sudden Disease }\end{array}$ & $\begin{array}{l}\text { Pregnancy } \\
\text { Chronic Illness }\end{array}$ \\
\hline 2. & Duration & Short & Long \\
\hline 3. & Realized & Not known & Known \\
\hline \multirow{2}{*}{4.} & Readiness & & \\
\cline { 2 - 4 } & 1. Emotion & No & Sincere (Ikhlas) \\
\cline { 2 - 4 } & 2. Financial & No & Ready \\
\hline \multirow{2}{*}{5.} & $\begin{array}{l}\text { Terminology } \\
\text { used }\end{array}$ & $\begin{array}{l}\text { (God) trials, } \\
\text { Disasters }\end{array}$ & $\begin{array}{l}\text { Destiny (Takdir), } \\
\text { Degenerative }\end{array}$ \\
\hline
\end{tabular}

The second social construction, the cause of hospitalization is imperative or in religious language as destiny. Compulsion is something that happens to the body and can not be avoided. When a Maduranese woman, Ms. Halisah (65 years) was 
livered, and a few years before her husband died of similar things, her son saw it as part of the "necessity" of his family. As if, the disease is inevitable. Indeed, in a number of religious and health theories, this word of necessity or destiny is in response to a limited knowledge of the disease. It will reduce stress in patients and family members.[22]-[24]

The necessity or destiny is not only understood in illness, but in the process of pregnancy and birth. Pregnancy and birth are part of the cycle in the family. Therefore, ready or not, the family will prepare new members. They are also aware of all the consequences of the process of pregnancy and birth. A mother is aware that asthma will interfere with the birth process. He accepts all these consequences. Similarly, other mothers should stay overnight because of high blood pressure at the time of the last weeks before the birth.

\section{B. Readiness and Ownership of Subsidized Health Insurance Card (BPJS Kesehatan PBI).}

In the first construction, "sick" as a disaster, the patient and his family are actually not ready both emotionally and financially. Decisions for hospitalization are no alternative. Mrs. Kusniati (35 years) who had been weak and asked her little mother (bulik) to take to the hospital because of his body weakness and shortness of breath due to low $\mathrm{Hb}$. The same thing was also experienced by Mrs. Mutmainah (31 years) from Kab. Sampang. He asked his brother, Rokhim (25 years old) to deliver on a motorcycle. Her stomach pain was not reduced. It is similar to Mr. Daryono who had an accident.

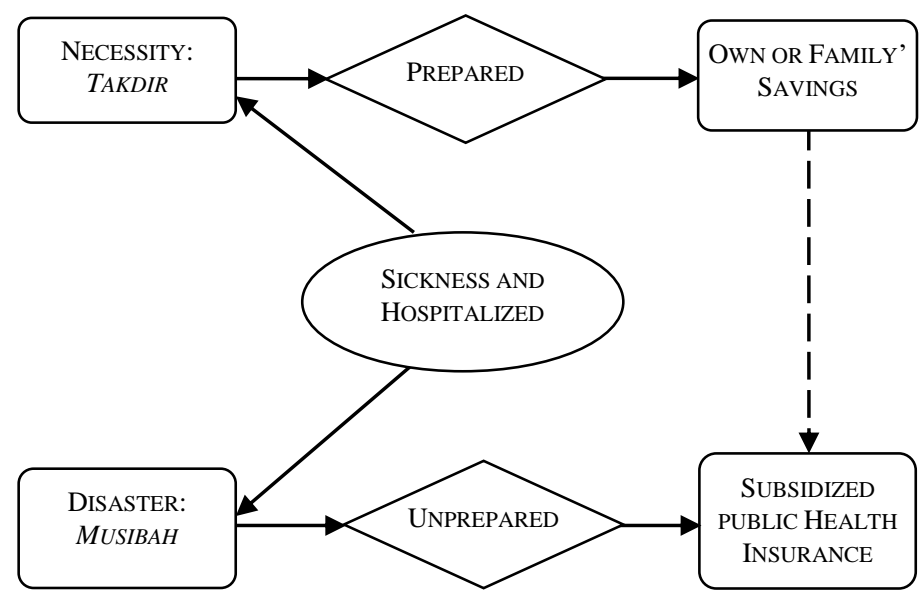

Fig. 2. Patient's and Their Family Social Constrution and Financial Preparation for Hospitalizing

Such conditions make the patient and the patient's family unprepared. Unpreparedness is not only an emotional issue, but it is also financially. Emotionally, they can not accept that the patient should be sick and hospitalized. Financially, they are also not ready. They do not always have savings. If any, the money is in small amounts. Therefore, it is not wrong if Mr. Daryono originally treated in private hospital, then ask for forced home and the next day choose to move in Public
Hospital (RSUD) while taking care BPJS PBI Subsidized Health Insurance card

This is different from those who interpret illness or the cause of hospitalization as a necessity. They experienced or predicted this condition well in advance. Pregnancy and birth are natural processes with all the risks. The risk of pregnancy can be identified when examined regularly in midwives, primary public health care (puskesmas) or hospital. The couple had been preparing not only for the birth process, but also the post-natal rituals. That is, they must have savings. Meanwhile, they have also prepared BPJS PBI Subsidized Health Insurance card. When unwanted things happen, they prefer to use the tube first, then afterwards with BPJS PBI Subsidized Health Insurance card.

The same thing is done for those who suffer from illness, whether by illness or accident. Patients or family members who live in a house have set aside their income for routine checks or hospitalization costs. This was done by Anton, son of Mr. Widiardi (Bantul), as well as Mrs. Hasniah, the son of Mrs. Halisah (Sampang). Moreover, they also prepare BPJS PBI Subsidized Health Insurance card, either as a consequence of Community Health Insurance (Jamkesmas) or Regional Community Health Insurance (Jamkesda), or self-cultivate by asking the village apparatus. With both cases, it is not true that poor families do not take into account future risks. It is not true that poor families are fatalistic, or resigned to circumstances. The problem lies there is no residual income to be set aside. On this preparation, they do not always use government health facilities, but look for the nearest health facility. It reduces transport costs.

\section{Family, Relatives and Neighbors as the Patient's Social Capital and His Family}

Some researchers say that every individual, family, community or community has social capital, in addition to other capital.[14], [25]-[27] This social capital is a network that can strengthen individuals, families, associations or communities in achieving certain goals or overcome the problem. In the case of this study, when a patient is sick, then admittedly or not, his family structure is actually impaired. Patients and their families must first use the daily expenditure money, savings money if any and so on to use the network of kinship or other. 


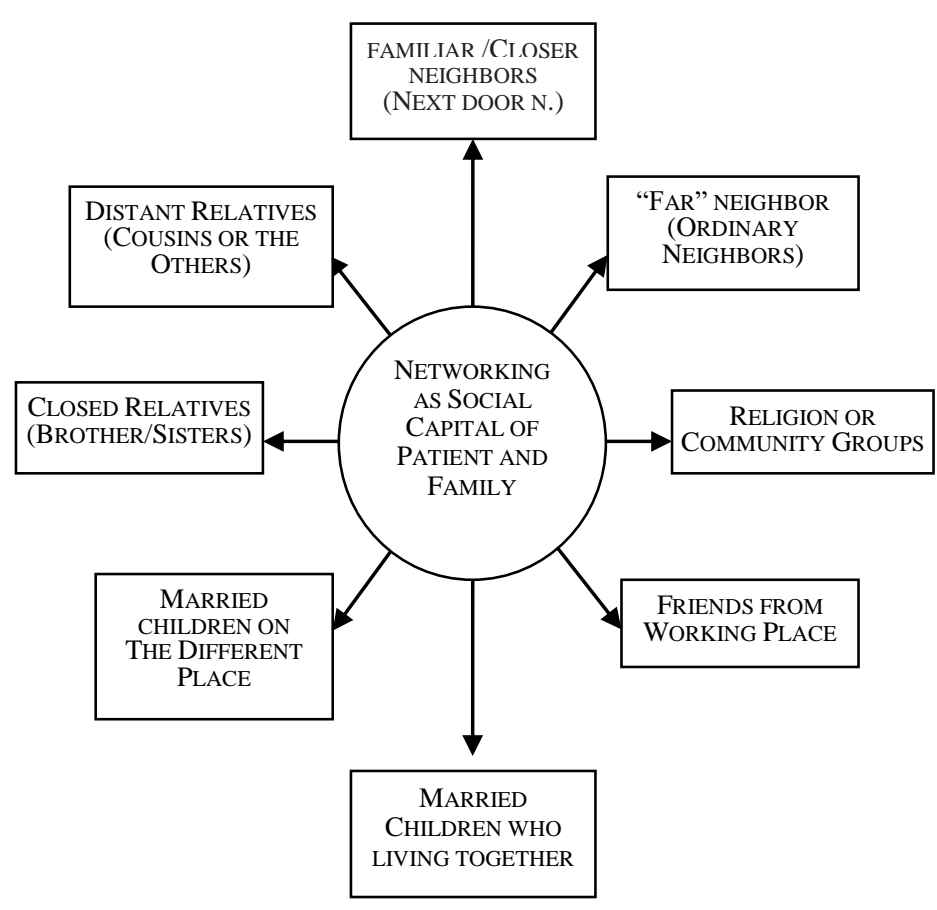

Fig. 3. Social Capital of Patient' and His/Her Families

From the results of questionnaires and scrutiny of informants in Kab. Bantul and Kab. Sampang, the involvement of people around patients and families became the key word as a strategy to address a number of issues beyond subsidized health insurance financing. The problems faced by the patient and his family, especially if the patient is still a housewife, among others, are: (1) who cares for a child left at home, especially if the child is a toddler or is still in primary school; (2) means of transportation used from home to hospital, and (3) expenses during hospitalization, especially for the waiter.

In fact, they are not alone. There is a lot of involvement in overcoming "non-medical" hospitalization problems. First, people who live in a house with patients become the first people to care for the patient. These people can be married, or they can not. In the case of Kab. Sampang, there is a tendency of parents to live in the old house that has been submitted or granted to the youngest child. Choice of grant is given to his daughter. The youngest child or married daughter automatically feeds his or her parents to death. Interestingly, they, the parents, both mother and father, do not want to bother her child by staying working. The money he receives is given to his grandchild for a snack or saving whenever they are sick. The same thing also happens in rural communities in Kab. Bantul.

The next person or family is a child who has grown up and does not live at home with the patient and his family. As a service to their parents, they are happy to help. They also wait for the patient at night. In addition, they also help expenses beyond BPJS Health dependence. If you are in a different city and away from the patient's home, they have time to come to visit and stay with the patient. After that, they will give money or ninggali (in Javanese) to their waiting siblings. In Kab. Sampang, in rural areas, the families of the children live around the house. This concept is known as tanean lajang. Nevertheless, today there are children who choose to go abroad. The money received is usually not recorded, but not so in Sampang. Some are interesting, they note and plan to pay back after the patient returns home. The reason is simple, they also have a need. Thus, the money must be returned. It did not happen in Bantul.

It is sad if it happens to a parent or rather a mother who only has an only child. The only child is an unmarried woman, as happened to Ms. Tuti Purwantini (46 years old) who suffers from acute gastric illness. He does not want to eat, especially after losing her husband 4 (four) years ago. He works as a janitor at a Christian Kindergarten. She was cared for by her daughter named Yuliana Astik Metaputri (24 years old). Yuliana is working as an honorary staff in public kindergarten (TK Negeri I) Kab. Bantul. She had to ask her sister (Budhe) for help from morning to evening. In the evening, he was assisted by his Pakde waiting for his mother. In addition to relatives, not infrequently neighbors are also involved as in the case of Mr. Widiardi (Bantul) and a number of patients in Kab. Sampang. Furthermore, social networks as social capital for patients and their families can be seen in Figure 3.

Not only in the circle of kinship, neighbors, co-workers and other social communities provide assistance to the sick also done by neighbors and co-workers. They visit the patient, bringing a parcel or fruit. This activity is actually part of the culture. The Maduranese called as nyapot and Javanese as a sambang. Because it is based on a distant emotional relation, it helps more financially.

However, that does not mean it does not have any social risks after hospitalization. The patient and his family still think that the problem is not over. After returning home, they felt obliged to "return" what they received from relatives, relatives, neighbors and office friends. Refund does not mean cash, but can also in the form of gratitude by sending rice and its side dishes in a basket (rantang). This gratitude can also be coupled with ritual events, such as baby event (selapanan). No matter how far away the patient's residence and his or her family are, these people must receive the "return". For poor families, the most severe returns are in the form of money. Therefore, one family of patients in Sampang Regency, for example, prefers to refuse granting people rather than having to return in the future. Social assistance turns into social debt. Social debt is a social risk to the family. The pattern of aid and social debt faced is shown in figure 4. 


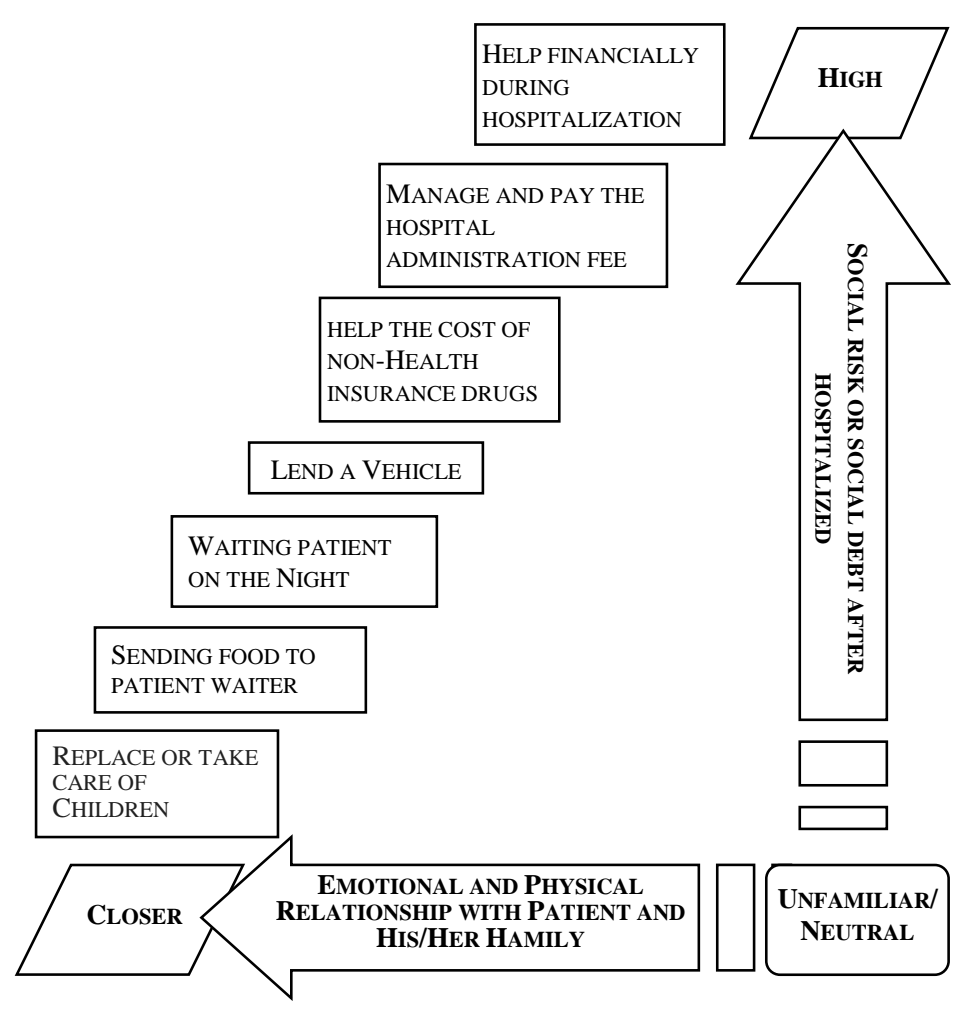

Fig. 4. Emotional and Physical Relationship and Social Risk/Social Debt

\section{CONCLUSION}

There are several things that can be concluded in this research. First, there is a difference in understanding the pain when it comes to the patient and his family when it needs to be hospitalized. Pain as a must and disaster. It is related to the cause of the patient should be hospitalized. The consequences of this understanding will relate to the readiness and fulfillment strategy of the financing. The use of subsidized sanitation insurance is used by poor families when having access to information about it. Relations with local communities, especially local governments, helped to facilitate access to subsidized insurance information. It is one of the positive social capital.

Secondly, there are various community groups that become social support for patients and their families. It is related to the social condition of the culture. In rural and rural communities, social support comes from relatives, the surrounding environment to special groups, such as denominations. Some of these also provide support to patients from urban areas. Kinship groups can start from those who live in the house until those who live away from patients from their families. The surrounding community environment is very strong in the periphery and rural areas. The proximity of distance and social relationships varies in the form of social assistance.
Third, social support turns out not only to be social capital, but also to turn into social debt for patients and their families. The inability to exchange due to economic conditions makes the aid as a burden on the family after discharge from the hospital. Nevertheless, they actually need it because there is a financing that should be spent privately during out of pocket. These things have shown that strong social capital does not always have a positive side, but also has a dark side as stated by Portes.[14], [15]

\section{ACKNOWLEDGMENT}

The research was conducted on the basis of financing from the Center for Humanities and Health Management. This research is chaired by M. Setyo Pramono, Ph.D. the lead author is one of its members. In addition to thanking the financiers, the article is fully dedicated to M Setyo Pramono, $\mathrm{Ph} . \mathrm{D}$. who had died in 2017 due to nasopharyngeal cancer. I am deeply indebted to the joint research opportunities since 2011. With him, I developed a research on the sociology of health. In addition, he entrusted me to apply ethnographic methods to complement the quantitative analysis

\section{REFERENCES}

[1] R. Chambers, Rural Development: Putting the Last First, 1st ed. Oxon, New York: Routledge, 2013.

[2] M. Claeson et al., "Health, Nutrition, and Population," in A Sourcebook for Poverty Reduction Strategies, 1st ed., J. Klugman, Ed. Washingto, DC: World Bank, 2002, pp. 201-230, 543-548.

[3] J. Boone, "Basic versus supplementary health insurance: access to care and the role of cost effectiveness," J. Health Econ., 2018.

[4] J. A. Nabhani, R. Kuang, H. Liu, L. Kwan, and M. S. Litwin, "Oncology: Prostate / Testis / Penis / Urethra Health Changes in Low Income Men Transitioning from a State Funded Prostate Cancer Program to Comprehensive Insurance," J. Urol., vol. 200, no. 1, pp. 74-81, 2018.

[5] M. Dillender, "Medicaid, Family Spending, and the Financial Implications of Crowd-Out," J. Health Econ., p. 55, 2017.

[6] A. Arment and S. Evers, "Cost of illness studies in health care: a comparison of two cases.," Health Policy (New. York)., vol. 261, no. 1, pp. 1-20, 1993.

[7] M. T. Hyyppä, Healthy Ties Social Capital, Population Health and Survival, 1st ed. Dordrecht: Springer Science+Business Media B.V, 2010 .

[8] S. Shiovitz-Ezra and H. Litwin, "Social Network Type and Health among Older Americans," in Social Capital as a Health Resource in Later Life: The Relevance of Context, 1st ed., F. Nyqvist and A. K. Forsman, Eds. Vaasa, Finland: Springer, 2015, pp. 15-33.

[9] S. A. Emmerling, K. S. Astroth, M. J. Kim, W. M. Woith, and M. J. Dyck, "A comparative study of social capital and hospital readmission in older adults," Geriatr. Nurs. (Minneap)., 2018.

[10] C. Herberholz and S. Phuntsho, "Social Science \& Medicine Social capital, outpatient care utilization and choice between di ff erent levels of health facilities in rural and urban areas of Bhutan," Soc. Sci. Med., vol. 211, no. December 2017, pp. 102-113, 2018.

[11] H. Murayama, K. Kondo, and Y. Fujiwara, "Social Capital Interventions to Promote Healthy Aging," in Global Perspectives on Social Capital and Health, 1st ed., I. Kawachi, S. Takao, and S. V. Subramanian, Eds. New York: Springer Science+Business Media B.V, 2013, pp. 205-238.

[12] J. Anchorena, L. Ronconi, and S. Ozawa, "Social Capital and Health in Low- and Middle-Income Countries," in The Economics of Social 
Capital and Health A Conceptual and Empirical Roadmap, 1st ed., S. Folland and L. Rocco, Eds. Singapore: World Scientific Publishing Co. Pte. Ltd., 2014, pp. 153-176.

[13] M. Rostila, Social Capital and Health Inequality in Eruopean Welfare States, 1st ed. New York, 2013

[14] A. Portes, "Social Capital: Its Origins and Applications in Modern Sociology," in Knowledge and Social Capital, 1st ed., E. L. Lesser, Ed. Butterworth-Heinemann, 2000, pp. 43-67.

[15] E. Villalonga-Olives and I. Kawachi, "The dark side of social capital: A systematic review of the negative health effects of social capital," Soc. Sci. Med., 2017.

[16] M. Hammersley and P. Atkinson, Ethnography: Principles in Practice., 3rd ed., vol. 15, no. 3. Oxon: Routledge, 1986.

[17] R. R. Kameny and D. J. Bearison, "Illness Narratives: Discursive Constructions of Self in Pediatric Oncology,” J. Pediatr., vol. 14, no. 2, pp. 73-79, 1999.

[18] M. Westerhaus, R. Panjabi, and J. Mukherjee, "Violence and the role of illness narratives," www.thelancet.com, vol. 372, no. 0, pp. 700-701, 2008.

[19] P. Goldie, "Narrative, emotion, and understanding," in Narrative Research in Health and Illness, B. Hurwitz, T. Greenhalgh, and V.
Skultans, Eds. Massachusetts: Blackwell Publishing Ltd, 2004, pp. 156167.

[20] Y. A. Walangit and F. X. S. Sadewo, "Modal Sosial Pasien Rawat Inap Etnis Madura," Paradigma, vol. 2, no. 1, pp. 1-5, 2014.

[21] A. Wibowo, "Faktor-faktor Penyebab pudarnya tradisi sambatan dalam Masyarakat Dusun Gamplong IV, Sumberrahayu, Moyudan, Sleman," Universitas Negeri Yogyakarta, 2010.

[22] K. Loewenthal, Religion, Culture and Mental Health, 1st ed. Cambridge: Cambridge University Press, 2006.

[23] S. Schieman, A. Bierman, and C. G. Ellison, Handbook of the Sociology of Mental Health. 2013.

[24] H. G. Koenig and H. J. Cohen, The Link between Religion and Health. Psychoneuroimmunology and the Faith Factor, 1st ed. Oxford: Oxford University Press, 202AD.

[25] C. Grootaert, D. Narayan, V. N. Jones, and M. Woolcock, "Measuring Social Capital," Washington, D.C., 18, 2004.

[26] N. Lin, Social Capital, A Theory of Social Structure and Action.pdf, 1st ed. Cambridge, 2001.

[27] P. Bourdieu, "The Forms of Capital," in Handbook for Theory and Research for the Sociology of Education, 1st ed., J. G. Richardson, Ed. Westport, CT: Greenwood, 1978, pp. 47-58. 